\title{
TESTING MEDICAL TREATMENTS: A RISK-BASED APPROACH TO DRUG REGULATION
}

\author{
Mattia Andreoletti ${ }^{1}$ \\ ${ }^{1}$ University of Turin
}

May 5, 2020

\begin{abstract}
In this paper I focus on the FDA regulation of medical treatments. As a matter of fact, since the advent of drug regulation in 1962, we have a variety of standards for testing the safety and the efficacy of treatments and products. I want to make explicit the reasons for explaining that variety. Here I argue that medical regulatory schemes are grounded on an implicit socio-political consensus on the risks involved by different medical interventions: the bigger the threat, the stricter the testing standards. Finally, by analysing the concept of risk, I claim that, from the point of view of regulators, innovative drugs might be not very different from medical devices or even surgical procedures, therefore lower testing standards are more defensible than what critics usually think.
\end{abstract}

\section{Hosted file}

Risk-based drug regulation.docx available at https://authorea.com/users/293560/articles/ 421571-testing-medical-treatments-a-risk-based-approach-to-drug-regulation 